\title{
Percutaneous Interventricular Septal Access Guided by Subcostal Echocardiography and Fluoroscopy for Ventricular Tachycardia Ablation in a Patient with Aortic and Mitral Mechanical Valves
}

\author{
DURSUN ARAS, MD, ${ }^{1}$ SERKAN TOPALOGLU, MD, ${ }^{1}$ OZCAN OZEKE, MD, ${ }^{1}$ FIRAT OZCAN, MD, ${ }^{1}$ \\ SERKAN CAY, MD, ${ }^{1}$ and ZEHRA GOLBASI, MD ${ }^{1}$
}

${ }^{1}$ Department of Cardiology, Turkiye Yuksek Ihtisas Training and Research Hospital, Health Sciences University, Ankara, Turkey

\begin{abstract}
Mechanical prosthetic aortic and mitral valves preclude either a retrograde aortic or transseptal approach to the left ventricular (LV) endocardium. Several operators have reported on the application of nonconventional techniques for ventricular tachycardia (VT) ablation including transventricular septal puncture, epicardial approach, transmechanical valve approach, transcoronary venous approach, and transapical approach. Incorporating transventricular access to the LV under intracardiac echocardiography (ICE) guidance has been previously attempted in $V T$ ablation procedures in patients with both aortic and mitral mechanical valves. However, while ICE is readily used in the United States, its use is less common in Europe, since the health insurance agencies largely do not cover the costs of ICE catheters. We therefore herein present a case of $V T$ ablation in the LV using a transventricular approach in a patient who underwent mechanical double valve replacement performed under subcostal echocardiographic and fluoroscopic guidance.
\end{abstract}

KEYWORDS. Ablation, aortic and mitral mechanical valves, double mechanical valve, transventricular septal access, ventricular tachycardia.
ISSN 2156-3977 (print) ISSN 2156-3993 (online) CC BY 4.0 license

(C) 2019 Innovations in Cardiac Rhythm Management

\section{Introduction}

Mechanical prosthetic aortic and mitral valves preclude either a retrograde aortic or transseptal approach to the left ventricular (LV) endocardium. Several operators have reported previously on the use of nonconventional techniques during ventricular tachycardia (VT) ablation such as transventricular septal puncture, ${ }^{1,2}$ epicardial approach, ${ }^{3,4}$ transmechanical valve approach, ${ }^{5}$

The authors report no conflicts of interest for the published content. Manuscript received September 20, 2018. Final version accepted December 4, 2018.

Address correspondence to: Ozcan Ozeke, MD, Türkiye Yüksek İhtisas Hastanesi, Kardiyoloji Klinigi, Ankara 06100, Türkiye.

Email: ozcanozeke@gmail.com. transcoronary venous approach, ${ }^{6}$ or transapical approach. ${ }^{7,8}$ We present a case of transventricular VT ablation in a patient with electrical storm and mechanical double valve replacement.

\section{Case report}

A 69-year-old male patient with nonischemic dilated cardiomyopathy was referred for VT ablation due to electrical storm. He had a history of double valve replacement and biventricular pacemaker implantation. Since his documented VT morphologies were compatible with the LV posterobasal and apical regions, we chose to perform transventricular crossing, as it was thought that it could be potentially difficult to reach all parts of the LV apex 
A

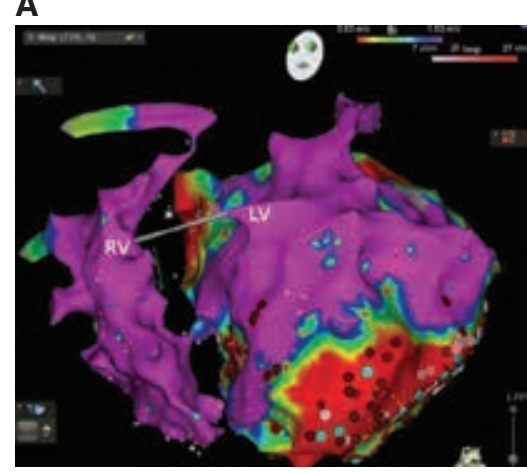

B

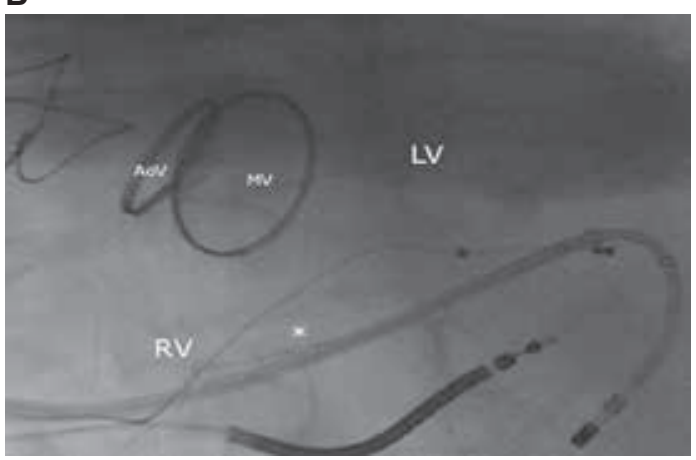

Figure 1: A: Left anterior oblique image obtained using the CARTO ${ }^{\circledR} 3$ three-dimensional electroanatomic mapping system (Biosense Webster, Diamond Bar, CA, USA). B: Right anterior oblique image obtained using the fluoroscopy shows the transventricular crossing of a 3.5-mm irrigated-tip ablation catheter $\left(^{*}\right)$. An extensive area of low bipolar voltage $(<1.5 \mathrm{mV})$ consistent with the scar was present in the inferolateral LV apex extending to the accessible mid-LV (A).

A

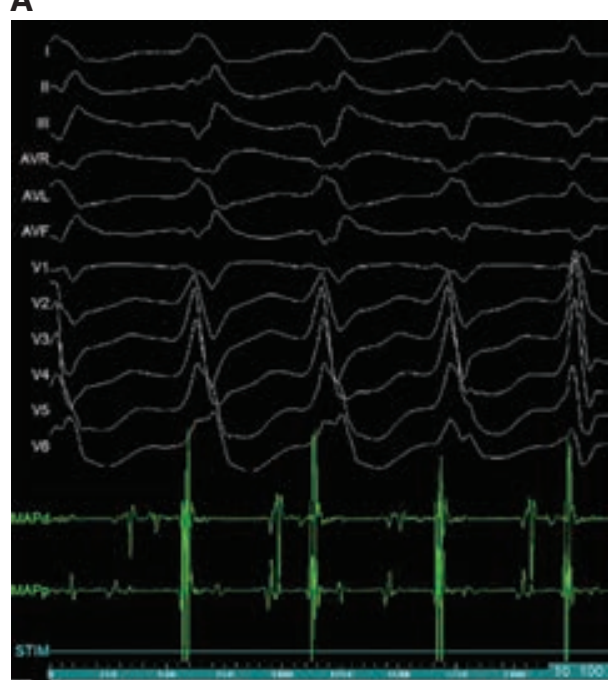

C
B

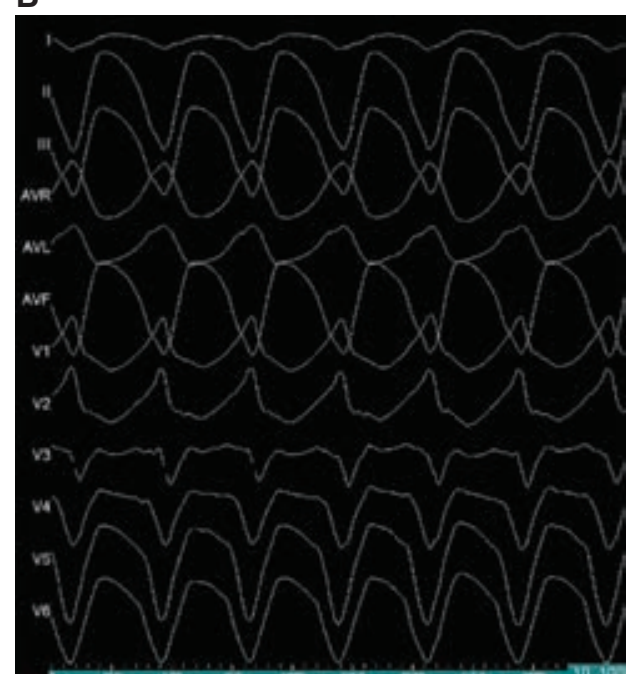

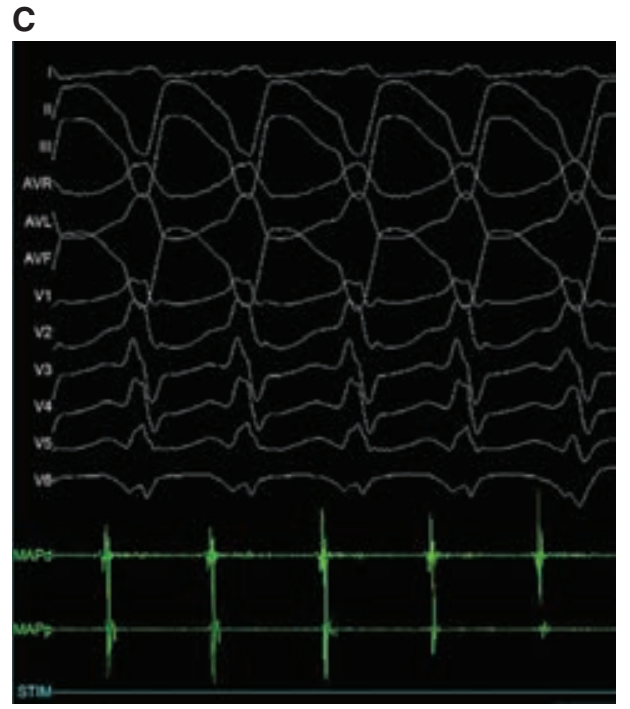

Figure 2: A, B, and C: Three different tachycardia morphologies induced and the areas of significant middiastolic potentials during ventricular tachycardia (A and C) ablated. AoV: prosthetic aortic valve; LV: left ventricle; MV: prosthetic mitral valve; $\mathrm{RV}$ : right ventricle. 
using transapical access. The right internal jugular vein was accessed, and a Swartz ${ }^{\mathrm{TM}}$ Braided SL1 Transseptal Guiding Introducer Sheath (Cardion, Brno, the Czech Republic) was advanced to the basal right ventricular septum. We preemptively prepared the Amplatzer ${ }^{\mathrm{TM}}$ Muscular Ventricular Septal Defect Occluder device (Abbott Laboratories, Chicago, IL, USA) as a bailout plan for use if there was a catastrophic septal defect at the time of removal. After confirming there was a safe distance from the coronary septal perforator branches with both left and right coronary angiography and no entrapment of the tricuspid septal leaflet by subcostal echocardiography (Figures 1A and 1B and Videos 1 and 2), the interventricular septum was crossed with a Brockenbrough needle under uninterrupted warfarin and intravenous heparin therapy. It was difficult to dilate and advance the aforementioned Swartz ${ }^{\mathrm{TM}}$ Braided SL1 sheath (Cardion, Brno, the Czech Republic) from the transventricular septum; however, the catheter manipulation was easy to perform after the crossing was complete. The three different VTs originating from the LV apical and posterobasal regions were induced (Figures $2 \mathrm{~A}$ and $2 \mathrm{~B}$ and Video 3 ) and late potential substrate ablation during sinus rhythm and the areas of the middiastolic potentials during VT (Figures 2A and 2C) were ablated. In total, the procedure lasted about 5.3 hours without intraprocedural complications or residual ventricular septal defect (Video 4). He recovered uneventfully and experienced one VT episode that responded to antitachycardia pacing therapy one day later. He was discharged five days after the procedure with heart failure therapy (ie, metoprolol, aldactone, furosemide, ramipril) and mexiletine. At present, this patient is being followed up with in the outpatient clinic.

\section{Discussion}

In patients with mechanical double valve replacement and VT, catheter ablation may be prevented by limited access to the LV. However, direct access to the LV cavity by way of a percutaneous LV apical puncture through the intercostal space overlying the apex or through a left minithoracotomy or left lateral thoracotomy is a viable option for the mapping and ablation of LV VTs. ${ }^{4,8}$ Although epicardial VT ablation is a potentially useful method in patients with mechanical aortic and mitral valves ${ }^{9}$ the coronary venous system approach ${ }^{6}$ or transventricular septal access ${ }^{1,2}$ have additionally been applied successfully in certain patient populations. Yamada et al. ${ }^{10}$ and Herweg et al. ${ }^{5}$ reported the successful ablation of LV VTs via a transseptal approach and the crossing of a mechanical mitral valve prosthesis. ${ }^{5}$ In the latter study, a recurrence of monomorphic VT at two months later required a second VT ablation procedure using the same transseptal-transmitral approach. ${ }^{5}$ Transventricular septal access to the LV has been also reported in transcatheter aortic valve implantation procedures under intracardiac echocardiography (ICE) guidance. ${ }^{11}$ The use of ICE during transventricular septal puncture has been recommended from the viewpoint of safety; however, while it is generally used in the United States, it is not common in Europe, as health insurance agencies do not cover the costs of ICE catheters. Subcostal echocardiography was particularly useful for the confirmation of no entrapment of the tricuspid septal leaflet at the transventricular access point in the current case. Coronary angiography should be performed to assess the presence of large septal coronary artery perforators at the region of the midinterventricular septum, where safe access could be attempted. ${ }^{1}$ Transventricular access by subcostal echocardiographic guidance may be considered as an alternative route, particularly in critically ill patients when conventional percutaneous transaortic or transmitral valve access approaches are not possible. ${ }^{12}$

\section{References}

1. Vaseghi M, Macias C, Tung R, Shivkumar K. Percutaneous interventricular septal access in a patient with aortic and mitral mechanical valves: a novel technique for catheter ablation of ventricular tachycardia. Heart Rhythm. 2013;10(7):1069-1073.

2. Santangeli P, Shaw GC, Marchlinski FE. Radiofrequency wire facilitated interventricular septal access for catheter ablation of ventricular tachycardia in a patient with aortic and mitral mechanical valves. Circ Arrhythm Electrophysiol. 2017;10(1):e004771.

3. Anh DJ, Hsia HH, Reitz B, Zei P. Epicardial ablation of postinfarction ventricular tachycardia with an externally irrigated catheter in a patient with mechanical aortic and mitral valves. Heart Rhythm. 2007;4(5):651-654.

4. Maury P, Marcheix B, Duparc A, et al. Surgical catheter ablation of ventricular tachycardia using left thoracotomy in a patient with hindered access to the left ventricle. Pacing Clin Electrophysiol. 2009;32(4):556-560.

5. Herweg B, Ilercil A, Sheffield CD, Caldeira CC, RindeHoffman D, Barold SS. Ablation of left ventricular tachycardia via transeptal approach and crossing of a mechanical mitral valve prosthesis. Pacing Clin Electrophysiol. 2010;33(7):900-903.

6. Najjar J, Bortone A, Boveda S, Albenque JP. Radiofrequency ablation of an epicardial ventricular tachycardia through the great cardiac vein in a patient with mitro-aortic mechanical prostheses. Europace. 2007;9(11):1069-1072.

7. Vurgun VK, Altin AT, Kilickap M, Candemir B, Akyurek O. Percutaneous transapical approach and transcatheter closure for ventricular tachycardia ablation. Pacing Clin Electrophysiol. 2018;41(3):334-337.

8. Hsieh CH, Thomas SP, Ross DL. Direct transthoracic access to the left ventricle for catheter ablation of ventricular tachycardia. Circ Arrhythm Electrophysiol. 2010;3(2):178-185.

9. Soejima K, Nogami A, Sekiguchi Y, et al. Epicardial catheter ablation of ventricular tachycardia in no entry left ventricle: mechanical aortic and mitral valves. Circ Arrhythm Electrophysiol. 2015;8(2):381-389.

10. Yamada T, McElderry HT, Doppalapudi H, Kay GN. Successful radiofrequency catheter ablation of ventricular tachycardia originating from underneath the mechanical prosthetic aortic valve. Pacing Clin Electrophysiol. 2008;31(5):618-620.

11. Liu L, Tozzi P, Ferrari E, von Segesser LK. The transventricular-transseptal access to the aortic root: a new route for extrapleural trans-catheter aortic stent-valve implantation. Eur J Cardiothorac Surg. 2011;39(5):635-641.

12. Ozeke O, Cay S, Ozcan F, Topaloglu S, Aras D. The reentry circuit and route in no entry left ventricle situations for ventricular tachycardia ablations. Pacing Clin Electrophysiol. 2018;41(6):678. 